This item was submitted to Loughborough's Research Repository by the author.

Items in Figshare are protected by copyright, with all rights reserved, unless otherwise indicated.

\title{
Re-refining the measurement of distress intolerance
}

\section{PLEASE CITE THE PUBLISHED VERSION}

http://dx.doi.org/10.1016/j.paid.2015.05.005

\section{PUBLISHER}

(c) Elsevier

\section{VERSION}

AM (Accepted Manuscript)

\section{PUBLISHER STATEMENT}

This work is made available according to the conditions of the Creative Commons Attribution-NonCommercialNoDerivatives 4.0 International (CC BY-NC-ND 4.0) licence. Full details of this licence are available at: https://creativecommons.org/licenses/by-nc-nd/4.0/

\section{LICENCE}

CC BY-NC-ND 4.0

\section{REPOSITORY RECORD}

Bebane, Saeed, Heather D. Flowe, and John Maltby. 2019. "Re-refining the Measurement of Distress Intolerance". figshare. https://hdl.handle.net/2134/21544. 
Re-refining the Measurement of Distress Intolerance

Saeed Bebane ${ }^{\mathrm{a}}$, Heather D. Flowe ${ }^{\mathrm{a}}$ and John Maltby ${ }^{\mathrm{a},{ }^{*}}$

${ }^{a}$ College of Medicine, Biological Sciences, and Psychology, Henry Wellcome Building, Leicester University, Lancaster Road, Leicester, England, LE1 9HN.

${ }^{*}$ Corresponding author. John Maltby, College of Medicine, Biological Sciences, and Psychology, Henry Wellcome Building, Leicester University, Lancaster Road, Leicester, England, LE1 9HN. Tel.: +44(0)1162522482. Fax: +44 (0)116229 7196 E-mail address: jm148@le.ac.uk 
Re-refining the Measurement of Distress Intolerance 


\begin{abstract}
The current study aims to present a parsimonious measure of five factors of distress intolerance as proposed by Zvolensky, Vujanovic, Bernstein, and Leyro (2010). Exploratory $(n=511)$ and confirmatory $(n=157)$ factor analytic studies of items from five established measures of distress intolerance suggest a 20 -item measure representing five dimensions of distress intolerance (uncertainty, ambiguity, physical discomfort, frustration, and negative emotion). A comparison of latent factor models suggests that a bifactor model may present the best fit to the data, reflecting the identification of a general factor of distress intolerance while also recognizing the multidimensionality of the five group factors. The current findings suggest a parsimonious measure of five factors of distress intolerance, though further research may consider method and measurement biases and the convergent and discriminant validity of the subscales.
\end{abstract}

Keywords: distress intolerance; uncertainty; ambiguity; discomfort; frustration. 


\section{RE-REFINING DISTRESS INTOLERANCE}

\section{Re-refining the Measurement of Distress Intolerance}

Given the plethora of measures that have been used to assess distress intolerance (either through distress intolerance or distress tolerance, and subsequently in this paper simply referred to as distress intolerance), there have been attempts recently to refine its measurement. McHugh and Otto (2012) were the first to comprehensively synthesize a number of distress intolerance measures. They tested whether distress intolerance is comprised of a single construct by analysing the latent factor structure of four measures, including the Anxiety Sensitivity Index (Peterson \& Reiss, 1992), the Frustration Discomfort Scale (FDS; Harrington, 2005), the Discomfort Intolerance Scale (DIS; Schmidt, Richey, \& Fitzpatrick, 2006), and the Distress Tolerance Scale (DTS; Simons \& Gaher, 2005). Factor analysis of the subscales scores supported a single-factor latent structure. Furthermore, McHugh and Otto (2012) identified 10 items from the subscales that had the highest degree of concordance with the latent structure. They proposed that these items could be used as an unidimensional measure of distress intolerance.

Bardeen, Fergus, and Orcutt (2013) employed eight indices of distress intolerance to assess the latter's measurement in line with Zvolensky et al.'s (2010) summary of the distress intolerance measurement literature, which explores different measures of distress intolerance that have been presented in the literature. The summary suggests that the distress intolerance construct is represented by five distress intolerance constructs: uncertainty, ambiguity, physical discomfort, frustration, and negative emotion. Bardeen et al confirmed this summary based on a factor analysis of scores from subscales derived from the Intolerance of Uncertainty Index-Part A (Carleton, Gosselin, \& Asmundson, 2010), the Intolerance of Uncertainty Scale (Buhr \& Dugas, 2002), the Multiple Stimulus Types Ambiguity Tolerance-I (McLain, 1993), the Tolerance of Ambiguity Scale-12 (Herman, Stevens, Bird, Mendenhall, \& Oddou, 2010, a revised version of 


\section{RE-REFINING DISTRESS INTOLERANCE}

Budner's (1962) 16-item version), the Somatosensory Amplification Scale (Barsky, Wyshak, \& Klerman, 1990), the DIS (Schmidt et al., 2006), the FDS (Harrington, 2005), and the DTS (Simons \& Gaher, 2005).

The present study integrates the approaches employed by McHugh and Otto (2012) and Bardeen et al. (2013). McHugh and Otto (2012) provide a parsimonious 10-item unidimensional measure of distress intolerance . Bardeen et al. (2013) provide evidence that distress intolerance comprises five factors. However, the existing literature does not suggest a parsimonious measure that also measures the five factors of distress intolerance. In this study, we aimed to identify individual items from the measures employed by McHugh and Otto (2012) and Bardeen et al. (2013) so that we could measure distress intolerance in terms of its lower-order constructs (uncertainty, ambiguity, physical discomfort, frustration, and negative emotion).

\section{Method}

\section{Samples.}

Two samples of data were collected. Sample 1 was used for an exploratory factor analysis (EFA) and Sample 2 for a confirmatory factor analysis (CFA).

The first sample comprised 511 respondents ( 82 males, 429 females) who were either undergraduates or postgraduates enrolled on university courses over a two-year period. The participants ranged in age from 18 to 36 years $(M=19.77$ years, $S D=2.40)$. They were predominantly of a white ethnicity $(60.7 \%$, with $12.3 \%$ and $11.4 \%$ reporting to be black and South Asian respectively).

The second sample allowed us to test whether the findings from the first sample were replicated in a non-student population. The second sample comprised 157 older adults (45 males and 112 females) aged from 18 to 58 years $(M=27.55$ years, $S D=7.9)$. These participants were 


\section{RE-REFINING DISTRESS INTOLERANCE}

also predominantly white $(72.6 \%$, with Asian being the next highest reported ethnicity) and single (46.5\%, with $45.9 \%$ living as married), with the most commonly reported occupations being sales/marketing/advertisting (14.6\%) or computer-related (10.8\%). The recruitment procedure combined opportunistic and snowball sampling, with social networking sites used firstly to contact participants, who were then asked to forward details of the study to acquaintances. Fourteen respondents were removed from the analysis because they were students, and 22 respondents did not complete the survey.

\section{Materials.}

Across their two studies, McHugh and Otto (2012) and Bardeen et al. (2013) employed nine scales, three of which featured in both studies. In choosing candidates from these nine scales for the current study we aimed to (a) have as much overlap as possible with the two previous studies, (b) obtain a five-factor structure of distress intolerance, (c) administer a number of items that were not too arduous for respondents to complete, and (d) facilitate an adequate item-torespondent ratio. The respondents in Sample 1 were asked to complete five distress intolerance scales.

The Intolerance of Uncertainty Scale (IUS; Buhr \& Dugas, 2002) was used to measure 'uncertainty' distress intolerance. The IUS comprises 27 items used to assess emotional, cognitive, and behavioural responses to ambiguous stimuli, the consequences of being uncertain, and endeavours to control the future. Responses are scored on a five-point scale ranging from 1 (not at all characteristic of me) to 5 (entirely characteristic of me).

The Tolerance of Ambiguity Scale (TAS: Budner, 1962) was used to measure the 'ambiguity' distress intolerance. The TAS comprises 16 items used to assess an individual's tendency to perceive ambiguous situations as desirable. It consists of three subscales: novelty, 


\section{RE-REFINING DISTRESS INTOLERANCE}

complexity, and insolubility. Responses are scored on a seven-point scale ranging from 1 (strongly agree) to 7 (strongly disagree ). Though Bardeen et al. (2013) used a shortened version of this scale, we employed all the items to provide a further full range of items from which to consider 'ambiguity' distress intolerance.

The Discomfort Intolerance Scale (DIS; Schmidt et al., 2006) was used to measure the 'physical discomfort' distress intolerance. The DIS comprises five items (from an original proposed seven items) that assess a person's ability to withstand uncomfortable physical sensations via intolerance of discomfort or pain and avoidance of physical discomfort. Responses are scored on a seven-point scale ranging from 0 (not at all like me) to 6 (extremely like me). We administered all the original seven itemsdevised by Schmidt et al. (2006) to provide a full consideration of 'physical discomfort' distress intolerance.

The Frustration Discomfort Scale (FDS; Harrington, 2005) was used to measure 'frustration' distress intolerance. The FDS comprises 35 items (with 7 items forming separate gratification and fairness subscales) used to measure a person's ability to tolerate discomfort, their emotional intolerance, and their ability to tolerate achievement frustration discomfort. Responses are scored on a five-point scale ranging from 0 (absent) to 4 (very strong).

The Distress Tolerance Scale (DTS; Simons \& Gaher, 2005) was used to measure 'negative emotion' distress intolerance. The DTS comprises 15 items used to assess an individual's ability to withstand emotional distress via tolerance, appraisal, absorption, and regulation. Responses are scored on a five-point scale ranging from 1 (strongly disagree) to 5 (strongly agree).

The participants in Sample 2 were asked to complete 20 items that we deemed suitable for measuring distress intolerance following the EFA that is outlined below. A change was made to 
standardize the response format to a seven-point scale with the following responses: 1 (strongly disagree) to 7 (strongly agree).

\section{Procedure.}

For both surveys, questionnaires were completed via an electronic survey system that was set up in such a way that the respondents had to answer all of the questions. For Sample 1, the software allowed the order of the administration of the scales to be randomized.

\section{Ethical Consent.}

The study procedure received ethical approval from an University Ethics Board.

\section{Results}

\section{Exploratory Factor Analysis.}

The first step of the analysis was to determine the factor structure of the items, using EFA to allow any such structure to emerge. The number of participants (511) to variables (100) ratio exceeded the recommended minimum ratio for EFA of 5 to 1 (with a minimum number of participants of 150) (Gorsuch, 1983). All items were subjected to maximum likelihood analysis (Kaiser-Meyer-Olkin measure of sampling adequacy $=.91$; Bartlett's test of sphericity, $\left.x^{2}=24000.39, d f=4950, p<.001\right)$.

The decision as to the number of factors to retain is crucial when carrying out EFA; this can be based on the K1 method (eigenvalues greater than one; Kaiser, 1960), a scree plot (Cattell, 1966), and/or a parallel analysis of Monte Carlo simulations (Horn, 1965). Reports have suggested that parallel analysis is the most accurate method for determining the number of factors, demonstrating the least variability and comparing favourably to the other methods (Ledesma \& Valero-Mora, 2007). Therefore, parallel analysis was used as the definitive guide. The ninth eigenvalue obtained using a maximum likelihood extraction $(18.95,6.40,4.87,4.21$, 


\section{RE-REFINING DISTRESS INTOLERANCE}

$3.15,2.75,2.11,1.83$, and 1.63 ) failed to exceed the ninth eigenvalue from the parallel analysis $(2.03,1.96,1.91,1.86,1.83,1.79,1.76,1.73$, and 1.70) calculated from 1,000 generated datasets with 511 cases and 100 variables, suggesting an eight-factor solution.

Therefore, an eight-factor solution (see Table 1) was sought, using promax rotation, as we expected the factors to be correlated, with delta set to 0. Meaningful loadings were assessed using the criteria of .32 (poor), .45 (fair), .55 (good), .63 (very good) or .71 (excellent) (Tabachnick \& Fidell, 2007). Using these criteria, 95 of the 100 items loaded above .32 on one of the factors, with four items loading at .32 or above (but equal to or below .45) across two factors. A truncated version of the analysis is presented in Table 1, listing the items by the order in which the factors loaded and the salience of each item to that factor. All loadings above .55 (i.e. good to excellent) are in bold, and the numbers of additional items (and range of loadings) that loaded on the factors but are omitted from the table are noted below the table.

- Insert Table 1 about here -

When considering these loadings, five factors emerge as having items with good to excellent loadings, with the first, second, third, fifth, and sixth factors reflecting Zvolensky et al.'s (2010) five-factor model of uncertainty, frustration, negative emotion, ambiguity, and physical discomfort respectively. The items from the five different measures map onto these five different factors. To further consider this finding we conducted a five-factor interpretation using a maximum likelihood extraction with promax rotation. Within this solution, 26 of the 27 items of the IUS loaded (between .36 and .78) on the first factor, 32 of the 35 items of the FDS loaded (between .32 and .69) on the second factor, all items of the DTS loaded (between .34 and .78) on the third factor (4.865, between .34 and .78$), 8$ of the 16 items of the TAS loaded (between .34 and .64) on the fourth factor, and 6 of the 7 items of the DIS loaded (between .36 and .90) on the 


\section{RE-REFINING DISTRESS INTOLERANCE}

fifth factor. These findings suggest a five-factor interpretation among the current items.

Therefore, we make two proposals: first, that five factors from the EFA can be used as a basis for measuring Zvolensky et al.'s (2010) five-factor summary of distress intolerance, and second, that five scales, using four items each, can be created using items that load on these factors under a good or better criteria.

The magnitudes of the correlations between the originally extracted five factors range from $r=.01$ (negative emotion and physical discomfort) to $r=.55$ (uncertainty and negative emotion), suggesting that the factors share no more than $30.25 \%$ common variance. The Cronbach's alpha coefficients for the five four-item scales (uncertainty, $\alpha=.82$; frustration, $\alpha=$ .71 ; negative emotion, $\alpha=.83$; ambiguity, $\alpha=.68$; physical discomfort, $\alpha=.82$ ) satisfy either the internal reliability criterion of $.6 \leq \alpha<.7$ (acceptable; one case) or that of $\alpha>.7$ (good; four cases; Kline, 1999).

\section{Confirmatory Factor Analysis.}

To explore the structural validity and stability of a five-factor interpretation of a 20 -item version of distress intolerance, the data collected from Sample 2 were used in a series of comparison CFAs. We compared the five-factor interpretation of the data against three models: (i) a unidimensional model proposing that all 20 items would load on one factor, reflecting an underlying latent factor of distress intolerance as suggested by McHugh and Otto's (2012) work, (ii) a higher-order factor model to examine whether the correlations between the first-order factors are explained in terms of a higher-order factor, and (iii) a bifactor model to allow for the identification of a single common construct (e.g. 'general distress intolerance') while also recognizing multidimensionality (five group factors of distress intolerance). 


\section{RE-REFINING DISTRESS INTOLERANCE}

The fit statistics for the four models are presented in Table 2. To assess the goodness-offit of the data, five statistics, and accompanying criteria, recommended by Hu and Bentler (1999) and Kline (2005) were used: the chi-square $\left(X^{2}\right)$, the comparative fit index (CFI), the non-normed fit index (NNFI), the root mean square error of approximation (RMSEA), and the standardized root mean square residual (SRMR). Additionally, we report the relative chi-square (CMIN/DF) as well as the chi-square and degrees of freedom. We used the following criteria to assess whether the model fit was adequate (noting that any chi-square test was likely to be significant due to the large sample size: (i) that the relative chi-square (CMIN/DF) should be less than 3 to be acceptable, (ii) that the CFI and NNFI should exceed .90 in order to be acceptable, (iii) that the RMSEA should not exceed .08 in order to be acceptable, and (iv) that for the SRMR values less than .08 would be acceptable.

- Insert Table 2 about here -

For the five-factor model of distress intolerance (1), the hierarchical higher-order factor, and the bifactor model, the fit statistics meet the aforementioned criteria for acceptability, with the models demonstrating measurement equivalence under the assumption that a $\Delta \mathrm{CFI}$ larger than .01 would be indicative of non-equivalence (Cheung \& Rensvold, 2002). Within these criteria, the findings suggest that the higher-order solution does not result in a significant decrease in model fit, and therefore provides a good explanation of the correlations among the lower-order factors (Brown, 2006). However, the use of a more conservative cutoff of .002 for $\Delta$ CFI has also been recommended (Meade, Johnson, \& Braddy, 2008). Using this criterion, the bifactor model demonstrates an improved set of goodness-of-fit statistics and may offer an improved explanation of the data. Figure 1 shows the standardized loadings and measurement error terms for the 20-item bifactor model. The variance accounted for the general factor in this 


\section{RE-REFINING DISTRESS INTOLERANCE}

model was $.51 \%$, with the distress intolerance group factors explaining $6 \%$ (uncertainty), $10.3 \%$ (frustration), 9.3\% (negative emotion), 13.2\% (ambiguity) and 10.2\% (physical discomfort).

Figure 1 shows the standardized loadings and measurement error terms for the 20 -item bifactor model. In terms of salience of loading on the factors, the average loading on the general factor was .52 , while the average loading across the group factors was .51 .

- Insert Figure 1 about here -

The Cronbach's alpha coefficients for the four-item scales (uncertainty, $\alpha=.79$; frustration, $\alpha=.82$; negative emotion, $\alpha=.85$; ambiguity, $\alpha=.83$; physical discomfort, $\alpha=.77$ ) exceed the internal reliability criterion of $\alpha>.7$ as good.

\section{Discussion}

Researchers have begun trying to define distress intolerance through parsimonious measures of the construct (e.g. McHugh \& Otto, 2012) and assessing the multifaceted nature of the construct (e.g. Bardeen et al., 2013). The findings of this paper integrate these approaches by proposing a 20-item measure that comprises five replicable factors that assess the uncertainty, ambiguity, physical discomfort, frustration, and negative emotion components of distress intolerance, consistent with Zvolensky et al.'s (2010) summary of possible distress intolerance factors within the literature. The findings also suggest that the bifactor model provides the best description of the data, identifying a general factor of distress intolerance (accounting for just over $51 \%$ of the common variance) while also recognizing the multidimensionality of the five group factors (together accounting for $49 \%$ of the variance). Noting the near equivalence of this variance shared and that the loadings are high for both the general factor and the group factors, the creation of both a general factor and subscales scores can be considered. Such a shortened 


\section{RE-REFINING DISTRESS INTOLERANCE}

multidimensional measure will be most useful when relatively few items can be administered in a research study, whether because time or space in the survey is in short supply.

Limitiations of the current findings include a series of method biases and measurespecific variance (Podsakoff, Mackenzie, Lee, \& Podsakoff, 2003) concerned with response sets in relation to instructions, wording, response format, number of items and subscales, reversal of items, and the use of five separate scales. Though the CFA analysis addresses some of these concerns by using the same instructions and response format, and by considering latent factors, there still exists the possibility that the current five-factor model is a reflection of measurement variance. Furthermore, though we have replicated the findings across two samples, the current findings apply to populations that differ in terms of participant-to-item ratio, age range, educational level, marital status, and gender balance. Therefore, further research is needed to explore the stability and dimensional nature of the factor structure of the scales among different populations, and much would be gained from considering how these subscales function, in terms of the convergent and discriminant validity of the scores on these subscales, particularly in terms of other measures of distress intolerance and personality, cognitive and affect systems.

In summary, the findings suggest that a 20 -item measure ('Distress Intolerance Five Factor - Short') representing a bifactor summary of distress intolerance emerges from the exploratory and confirmatory factor analysis of items from five established measures of distress intolerance. The resulting tool includes a unique combination of items that is not currently used by any other single distress intolerance measure, and it is recommended that further research and practice concerning distress intolerance may benefit from using this measure. 


\section{References}

Bardeen, J. R., Fergus, T. A., \& Orcutt, H. K. (2013). Testing a hierarchical model of distress tolerance. Journal of Psychopathology and Behavioral Assessment, 35(4), 495-505. http://dx.doi.org/10.1007/s10862-013-9359-0.

Barsky, A. J., Wyshak, G., \& Klerman, G. L. (1990). The somatosensory amplification scale and its relationship to hypochondriasis. Journal of Psychiatric Research, 24(4), 323-334. http://dx.doi.org/10.1016/0022-3956(90)90004-A

Brown, T. A. (2006). Confirmatory factor analysis for applied research. New York: Guilford Press.

Budner, S. (1962). Intolerance for ambiguity as a personal variable. Journal of Personality, 30(1), 29-50. http://dx.doi.org/10.1111/j.1467-6494.1962.tb02303.x

Buhr, K., \& Dugas, M. J. (2002). The intolerance of uncertainty scale: Psychometric properties of the English version. Behaviour Research and Therapy, 40(8), 931-945. http://dx.doi.org/10.1016/S0005-7967(01)00092-4

Carleton, R. N., Gosselin, P., \& Asmundson, G. J. G. (2010). The intolerance of uncertainty index: Replication and extension with an English sample. Psychological Assessment, 22(2), 396-406. http://dx.doi.org/10.1037/a0019230

Cattell, R. B. (1966). The scree test for the number of factors. Multivariate Behavioral Research, 1(2), 245-276. http://dx.doi.org/10.1207/s15327906mbr0102_10

Cheung, G. W., \& Rensvold, R. B. (2002). Evaluating goodness-of-fit indexes for testing measurement invarance. Structural Equation Modeling, 9(2), 233-255. http://dx.doi.org/ 10.1207/S15328007SEM0902_5

Gorsuch, R. L. (1983). Factor analysis (2nd ed.). Hillsdale, NJ: Erlbaum. 


\section{RE-REFINING DISTRESS INTOLERANCE}

Harrington, N. (2005). The Frustration Discomfort Scale: Development and psychometric properties. Clinical Psychology \& Psychotherapy, 12(5), 374-387. http://dx.doi.org/10.1002/cpp.465

Herman, J. L., Stevens, M. J., Bird, A., Mendenhall, M., \& Oddou, G. (2010). The tolerance for ambiguity scale: Towards a more refined measure for international management research. International Journal of Intercultural Relations, 34(1), 58-65. http://dx.doi.org/10.1016/j.ijintrel.2009.09.004

Horn, J. L. (1965). A rationale and test for the number of factors in factor analysis. Psychometrika, 30(2), 179-185. http://dx.doi.org/10.1007/BF02289447

Hu, L. T., \& Bentler, P. M. (1999). Cutoff criteria for fit indexes in covariance structure analysis: Conventional criteria versus new alternatives. Structural Equation Modeling, 6(1), 1-55. http://dx.doi.org/10.1080/10705519909540118

Kaiser, H. F. (1960). The application of electronic computers to factor analysis. Educational and Psychological Measurements, 20(1), 141-151. http://dx.doi.org/10.1177/001316446002000116

Kenny, D. A. (1979). Correlation and causation. New York, Wiley.

Kline, P. (1999). The handbook of psychological testing (2nd ed.). London: Routledge.

Kline, R. B. (2005). Principles and practice of structural equation modeling (2nd ed.). New York: Guilford Press.

Ledesma, R. D., \& Valero-Mora, P. (2007). Determining the number of factors to retain in EFA: An easy-to-use computer program for carrying out parallel analysis. Practical Assessment, Research \& Evaluation, 12(2). Retrieved September 22, 2014, from http://pareonline.net/getvn.asp? $v=12 \& n=2$ 


\section{RE-REFINING DISTRESS INTOLERANCE}

McHugh, R. K., \& Otto, M. W. (2012). Refining the measurement of distress intolerance. Behavior Therapy, 43(3), 641-651. http://dx.doi.org/10.1016/j.beth.2011.12.001

McLain, D. L. (1993). The MSTAT-I: A new measure of an individual's tolerance for ambiguity. Educational and Psychological Measurement, 53(1), 183-189. http://dx.doi.org/ $10.1177 / 0013164493053001020$

Meade, A. W., Johnson, E. C., \& Braddy, P. W. (2008). Power and sensitivity of alternative fit indices in tests of measurement invariance. Journal of Applied Psychology, 93(3), 568592. http://dx.doi.org/10.1037/0021-9010.93.3.568

Peterson, R. A., \& Reiss, S. (1992). Anxiety sensitivity index manual (2nd ed.). Worthington, DC: International Diagnostic Services.

Podsakoff, P. M., Mackenzie, S. B., Lee, J., \& Podsakoff, N. P. (2003). Common method biases in behavioral research: A critical review of the literature and recommended remedies. Journal of Applied Psychology, 88(5), 879-903. http://dx.doi.org/10.1037/00219101.88.5.879

Schmidt, N. B., Richey, J. A., \& Fitzpatrick, K. K. (2006). Discomfort intolerance: Development of a construct and measure relevant to panic disorder. Journal of Anxiety Disorders, 20(3), 263-280. doi:10.1016/j.janxdis.2005.02.002

Simons, J., \& Gaher, R. (2005). The Distress Tolerance Scale: Development and validation of a self-report measure. Motivation and Emotion, 29(2), 83-102. http://dx.doi.org/10.1007/s11031-005-7955-3

Tabachnick, B. G., \& Fidell, L. S. (2007). Using multivariate statistics (5th ed.). Boston, MA: Allyn and Bacon. 
Zvolensky, M. J., Vujanovic, A. A., Bernstein, A., \& Leyro, T. (2010). Distress tolerance:

Theory, measurement, and relations to psychopathology. Current Directions in Psychological Science, 19(6), 406-410. http://dx.doi.org/10.1177/0963721410388642 


\section{Footnotes}

(1) In accordance with classical test theory for verifying measurement models (e.g. Kenny, 1979), the chi-square difference test and $\Delta \mathrm{CFI}>.01$ criterion showed that the congeneric model for the five-group factor model presented a better fit of the data than either the tau-equivalent model $(\Delta \mathrm{CMIN}=23.57, \Delta \mathrm{df}=7, p=.001 ; \Delta \mathrm{CFI}=.015)$ or the parallel model $(\Delta \mathrm{CMIN}=46.16, \Delta \mathrm{df}=$ $15, p<.001 ; \Delta \mathrm{CFI}=.077)$. 
Table 1

Maximum Likelihood Extraction with Promax Rotation of the Items from the Distress Intolerance Scales.

\begin{tabular}{|c|c|c|c|c|c|c|c|}
\hline & \multicolumn{7}{|c|}{ Factor } \\
\hline & 12 & 3 & 4 & 5 & 6 & 7 & 8 \\
\hline 1. ...... uncertainty makes me vulnerable. (IUS17) & $.816-.121$ & .085 & -.082 & -.018 & .044 & 4.072 & .004 \\
\hline 2. ...... can't go forward. (IUS14) & $.792-.093$ & -.043 & .028 & -.051 & .035 & 5.019 & .118 \\
\hline 3. ...... taken by surprise. (IUS19) & .763 .004 & -.074 & -.002 & .007 & .012 & $2-.109$ & -.225 \\
\hline 4. ...... uncertain situations. (IUS25) & .755 .019 & -.084 & .064 & .043 & .012 & $2-.059$ & -.022 \\
\hline 5. ...... I am not first rate. (IUS13) & $.754-.094$ & -.149 & -.032 & .044 & .038 & 3.121 & .260 \\
\hline 6. ...... I can't function very well. (IUS15) & $.731-.066$ & -.008 & -.133 & -.041 & -.005 & .170 & .160 \\
\hline 7. ...... keeps me from living a full life. (IUS9) & .719 .047 & .021 & .003 & -.067 & -.084 & $4-.196$ & -.040 \\
\hline 8. ...... events upset me greatly. (IUS7) & $.718-.077$ & .047 & -.005 & -.041 & .006 & 6.002 & -.177 \\
\hline 9. ...... don't know what will happen tomorrow. (IUS5) & $.705-.123$ & .052 & .038 & $-.022-$ & -.023 & 3.061 & -.142 \\
\hline 10. ....... ambiguities in life. (IUS26) & .699. 082 & .109 & -.016 & -.037 & -.062 & $2-.062$ & -.137 \\
\hline 11. ...... doubt can stop me from acting. (IUS20) & 696.101 & -.110 & .015 & -.019 & -.027 & 7.009 & -.120 \\
\hline 12. ...... I lack confidence. (IUS22) & $.673-.098$ & .059 & .027 & .098 & .051 & 1.089 & .051 \\
\hline 13. ...... uneasy, anxious, or stressed. (IUS6) & $.666-.040$ & .119 & -.088 & .049 & -.005 & 5.150 & -.068 \\
\hline 14. ....... uncertainty paralyses me. (IUS12) & $.655-.099$ & .009 & .212 & -.021 & .030 & .112 & .159 \\
\hline 15. ...... sleeping soundly. (IUS24) & $.638-.071$ & .126 & -.043 & -.071 & -.122 & $2-.088$ & .020 \\
\hline
\end{tabular}


16. ...... where they are going with their lives. (IUS16)

17. ...... look ahead so as to avoid surprises. (IUS10)

18. ...... frustrates me not having all the information. (IUS8)

19. ...... unfair that other people seem sure. (IUS23)

20. ...... what the future has in store for me. (IUS18)

21. ...... unforeseen event can spoil everything. (IUS11)

22. ...... organize everything in advance. (IUS21)

Four more items from the IUS loaded from .34 to .53 on this factor.

23. ...... people stand in the way of what I want. (FDS10)

24. ...... tolerate being overlooked. (FDS29)

25. ...... treated with disrespect. (FDS33)

26. ...... having to change when others are at fault. (FDS22)

27. ...... left in the dark with no explanations. (FDS31)

28. ...... being taken for granted. (FDS14)

29. ...... been treated unjustly. (FDS30)

30. ...... other people's bad or stupid behaviour. (FDS35)

31. ..... things that involve a lot of hassle. (FDS21)

Nineteen more items from the FDS loaded from .32 to .54 on this factor.

32. ...... feeling distressed or upset. (DTS3)

33. ...... ashamed of myself when I feel distressed. (DTS11)
.626-.024 .052-.182 .034 .022-.103 .057

$\mathbf{. 5 8 7} .040-.052 .078 .058-.014-.015-.383$

$\mathbf{5 8 4} \quad$.155-.043-.128 $\quad 055 \quad 058$.085-.322 .569-.089.077. 201 .051-.014-.106 .046 $\mathbf{5 6 5}$.157-.039-.051 .060 .021.114-.276

.560 .089-.065 .021-.044-.063-.055-.152 $\mathbf{5 5 7} .059-.049$.249 .085-.011 .120-.339

-.026 .643-.180-.004 .014-.020.251.071 -.110.632.070.049-.035-.061-.071-.092 -.139.630 .007-.097-.063.010.060-.163 -.089.620 .027-.189.049.009-.060--.071 $.032 \quad$.595-.018-.295 $.050 \quad .042-.128 \quad .072$ -.095 .594-.129-.004-.059-.049 .176-.015 -.149 .582-.012. 169.026.011.048-.118 076 .565-.226.083.061.047-.040-.103 183 .560-.124 .050-.098.134-.108 .057 079-.009-.785-.011-.008.008.035.025 .051 .010-.778-.183-.005-.032 .018.006 
34. ...... distressed or upset is unbearable. (DTS1)

35. ...... feelings of distress are so intense. (DTS4)

36. ...... distress or being upset scares me. (DTS12)

37. ...... concentrate on how bad the distress actually feels. (DTS15)

38. ......other people seem to be able to tolerate. (DTS9)

39. ...... all I can think about is how bad I feel. (DTS2)

40. ...... nothing worse than feeling distressed or upset. (DTS5)

41. ...... as well as most people. (DTS6) (R)

Four more items from the DTS loaded from .47 to .53 on this factor.

42. ...... acquire similar values and ideals. (TAS15)

Nine more items from the TAS, FDS, IUS and DTS loaded from .32 to .53 on this factor.

43. ...... wonder about your way of looking at things. (TAS16) (R)

44. ...... fun to tackle a complicated problem. (TAS6) (R)

45. ...... interesting and stimulating people. (TAS8) (R)

46. ...... fit their lives to a schedule. (TAS4) (R)

Four more items from the TAS loaded from .41 to .47 on this factor.

47. ...... great deal of physical discomfort. (DIS1) (R)

48. ...... high pain threshold. (DIS2) (R)

49. ...... take steps to relieve the discomfort. (DIS6)

50. ...... more sensitive to feeling discomfort. (DIS7)
109-.021-.760-.039-.101-.028-.030-.055

-.096 .105-.753-.006.008.069.082-.011

-.042 .135-.699-.207-.031-.034-.078 .023

$-.029-.069-.677 .145 .008-.084-.030 \quad .043$

-.075 .018-.658 $\quad 138$.016-.074-.004.053 $.002-.060-.658$.105-.091-.050 .085 .065 -.018.030-.581 .048-.107-.028-.030 .034 -.079 .019-.567-.185.168.051.074.093

$.019 .045-.032-.554-.024-.037 \quad 034 \quad .003$

.012-.003 .027-.102 .760-.017-.022 .027

-.045-.061 098 301 .599.011-.002.

$039.060 .044-.319 .564-.070-.094 .228$

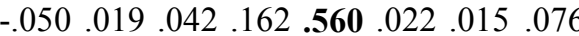

013-.023-.053.033.004.899-.064-.044

-.018-.068.006.056.016 .838-.073-.025

-.075-.013 .060-.086 032 .598 $.018-.045$

-.088 .063-.002 .094-.023 .587-.033-.012 
Two more items from the DIS loaded from .37 to .39 on this factor.

51. ...... frustration of not achieving my goals. (FDS8)

-.027 .081 .012 .038 .026-.026 .560-.023

One more item from the FDS loaded .38 on this factor.

$.017 .220 .020-.031-.027-.060 . \underline{386} .019$

Key: IUS = Intolerance of Uncertainty Scale; TAS = Tolerance of Ambiguity Scale; DIS = Discomfort Intolerance Scale; FDS = Frustration Discomfort Scale; DTS = Distress Tolerance Scale.

NB: Six items from the FDS, TAS and DIS crossloaded on factors or did not load above .32 on any factor. All items have been coded

to indicate greater levels of distress intolerance, items marked with (R) having been reversed. Due to copyright reasons, each item's wording has been abbreviated. The full wording of each item is available in the respective publication. 
RE-REFINING DISTRESS INTOLERANCE

Table 2

Confirmatory Factor Analysis Fit Statistics for the Different Models Proposed for the 20-item Distress Intolerance Scale.

\begin{tabular}{lllllllll}
\hline & $x 2$ & df & $p=<$ & CMIN/DF & CFI & NNFI & RMSEA & SRMR \\
\hline Unidimensonal & 683.830 & 170 & .000 & 4.023 & .617 & .572 & .139 & .107 \\
Five-factor lower-order & 272.874 & 160 & .000 & 1.705 & .916 & .900 & .067 & .061 \\
Higher-order & 274.425 & 165 & .000 & 1.663 & .918 & .906 & .065 & .062 \\
Bifactor & 250.096 & 150 & .000 & 1.667 & .925 & .905 & .065 & .055 \\
\hline
\end{tabular}


Figure 1

Standardardized Loadings (with measurement error terms in parentheses) for the 20-item Distress Intolerance Scale Bifactor Structure.

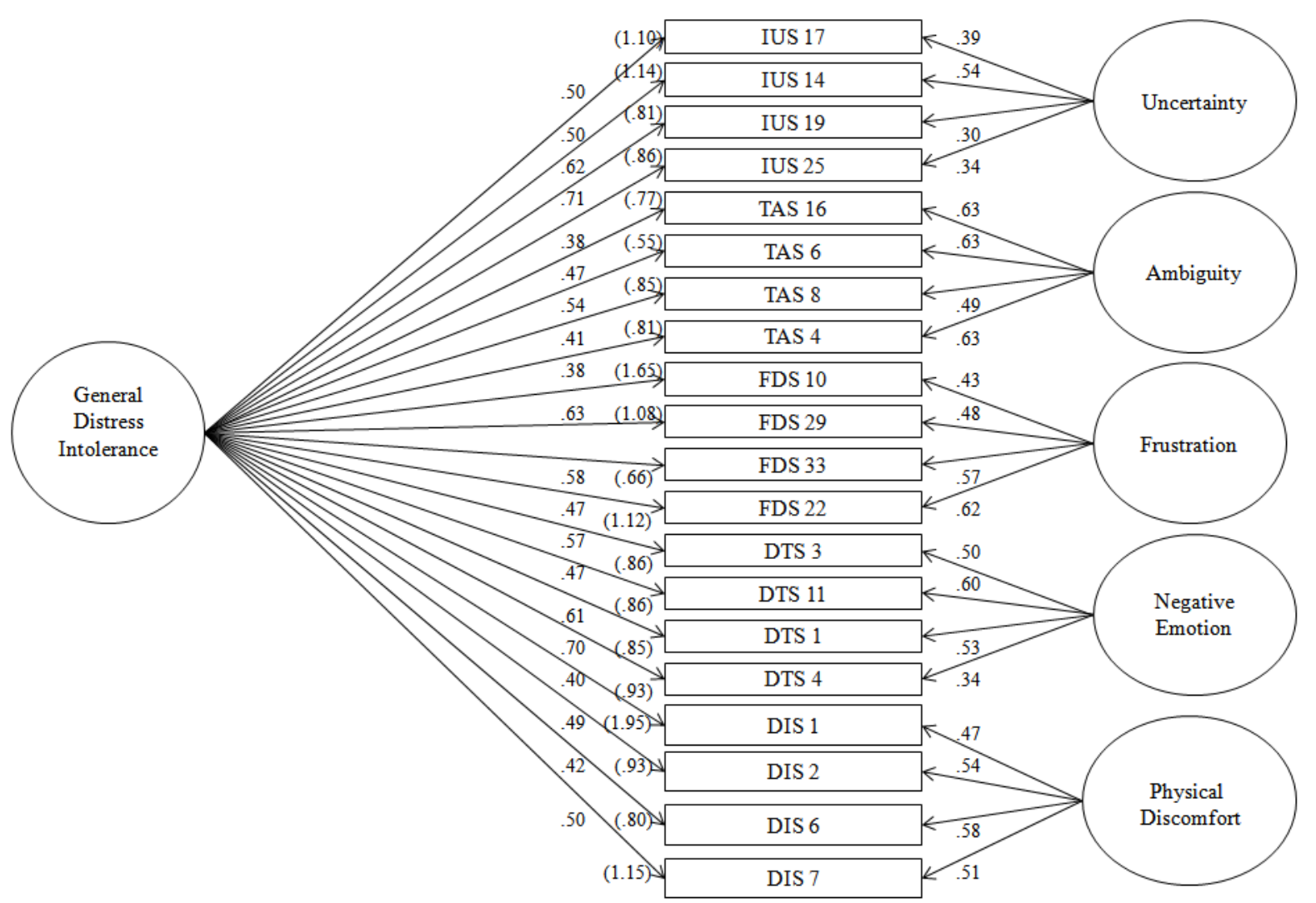

Key: IUS = Intolerance of Uncertainty Scale (Buhr \& Dugas, 2002); TAS = Tolerance of Ambiguity Scale (Budner, 1962); DIS = Discomfort Intolerance Scale (Schmidt et al., 2006); FDS = Frustration Discomfort Scale (Harrington, 2005); DTS = Distress Tolerance Scale (Simons \& Gaher, 2005). All items have been recoded to indicate greater levels of distress intolerance. 